\title{
Reviewing the boundaries of health law - new directions and dimensions: editorial
}

\author{
JoHn COGgon AND JUdY LAING
}

Centre for Health, Law, and Society, University of Bristol Law School

\begin{abstract}
$\mathrm{I}_{\mathrm{t}}^{\mathrm{t}}$ is an important and exciting time for scholars working at the intersections between law and health. The scope of our study is expanding in its practical reach, the range of disciplinary approaches that we employ, and in relation to our learning from, collaborations with, and influence on partners, actors, and agencies outside of academia; including those affected by, regulated by, and involved in the production of health law. We were delighted to mark this expansion with the founding, in October 2017, of the University of Bristol's Centre for Health, Law, and Society (CHLS), ${ }^{1}$ and, consequent to the Centre's launch event, ${ }^{2}$ the production of this special issue of the Northern Ireland Legal Quarterly. Our aim with CHLS - which draws together colleagues with wide-ranging interests, expertise, and practical experience in health law - is to push through the traditional boundaries of the field of healthcare ethics and law, and to explore new directions and dimensions; to identify how we should reconfigure the historical, conceptual, and practical reach of the field, and advance its potential to represent the best of rigorous research as a simultaneously theoretical and applied area of study. This special issue is a marker of, and contribution to, that aim.
\end{abstract}

As identified in Margaret Brazier and Jonathan Montgomery's opening paper ("Whence and whither "modern medical law?"), which takes a long view on the history of the field, there are currently significant challenges confronting health law, at both an academic and a practical level: some challenges are more pervasive (e.g. the impacts of Brexit, austerity); some are rooted in the healthcare sector (e.g. questions regarding regulation of and in the NHS); some derive from the expansion of health as a concern across sectors, and entailing both the traditional micro- and the less explored macrolevel concerns; and some obtain from the continued (relative) neglect of areas of concern (such as mental ill health). With such challenges in mind, the following six papers seek to shine a spotlight on areas of importance, and on critical and practical approaches, that are too easily neglected in health law. For example, our contribution ('Exploring new paradigms in mental health and capacity law: persons, populations, and parity of esteem') focuses on mental health inequalities and the significance of law to a population health approach to achieving better mental health and wellbeing; Albert Sanchez-Graells ('Centralisation of procurement and supply chain management in the

1 See $<$ www.bristol.ac.uk/law/research/centres-themes/chls $>$.

2 See $<$ www.bristol.ac.uk/law/research/centres-themes/chls/about $>$. 
English NHS: some governance and compliance challenges') explores the impact of the new model for NHS procurement on the delivery of care in the NHS, and key challenges for assuring legal oversight. The collection's aims to push agendas that link interdisciplinary insights with practice are represented, for example, in Oliver Quick and Catherine Kelly's historical analysis applied in the area of patient safety and achieving candour in the NHS ('The legal duty of candour in healthcare: the lessons of history?)'; and in Dave Archard's paper ("My child, my choice": negotiating disagreement between doctors and parents'), which examines the place of philosophical commitments in health law and public debate. And the special issue's aims to examine and contribute to ensuring the coherent expansion of the field, both in terms of coverage and critical approaches, are illustrated, amongst others, in Keith Syrett's paper ('Healthcare resource allocation in the English courts: a systems theory perspective'), which considers the novel application of systems theory as a tool for explication and evaluation of the relationship between law and allocative decision-making; and the critical feminist perspective, re-enforced through original empirical research and doctrinal legal analysis, in the paper by Louise Austin and Sheelagh McGuinness ('Reproductive loss and disposal of pregnancy remains').

As well as the extended articles, we are delighted to include legal and academic commentaries, which further highlight the expansive nature of health law as an academic and practical agenda. Jane Rooney's case note on extraterritorial corporate liability for environmental harm reinforces the potential to move in new directions, highlighting how human rights can play a much stronger role than traditional tort law mechanisms to protect citizens across the globe from environmental harms which damage their health and wellbeing. Transcending traditional boundaries is a key theme in Peter Dunne's legislative note on the new law to affirm the 'diverse' legal gender of persons who experience intersex variance in Germany. He welcomes the introduction of the new law, but at the same time offers some important critiques on the limitations of the German approach. We are also pleased to include book reviews on topics that push the boundaries of health law. The first, from Paul Skowron, on Charles Foster and Jonathan Herring's Depression: Law and Ethics, emphasises the importance of interdisciplinary legal studies regarding mental health; and the second, a review by Louise Hatherall of Benjamin Meier and Lawrence Gostin's latest edited collection on Human Rights in Global Health: Rights-based Governance for a Globalizing World, underscores the importance of international legal norms and trans-jurisdictional health challenges.

Our hope is that this rich collection of essays is indicative of some of the challenges and proper directions for the next generation of health law scholarship, and represents well the contributions that we anticipate will be made by scholars across the field, including from within CHLS. We are both honoured to be the founding Co-Directors of the Centre, and proud that it spans such an impressive range of research expertise, as evidenced by the breadth and depth of contributions from 11 of CHLS's members to this collection. We are grateful to the University of Bristol Law School for its support for the establishment of the Centre, for the launch event itself, and in the ongoing work of CHLS. We thank as well Professor John Iredale, Pro Vice-Chancellor (Health) at the University of Bristol, for his support at that event and his subsequent, continued encouragement. We would also wish here to thank the participants and attendees at the CHLS launch for their constructive contributions and comments, as well as to all of the contributors to this collection - both colleagues within and beyond CHLS - for sharing their insights and ideas. In the production of this special issue, many academic colleagues have given generously of their time to assist with the anonymous review process, 
for which we give our thanks. Finally, we would like to express our gratitude to Marie Selwood for her editorial assistance and efficiency, and to Mark Flear, the Chief Editor of the Northern Ireland Legal Quarterly, and other members of the Editorial Board, for supporting the scholarship in this special issue. 
